\title{
Fazit und allgemeine Hinweise zur Kassenbuchführung
}

Es wird bisher keinem Unternehmer gesetzlich vorgeschrieben, dass er für Zwecke der Kassenbuchführung eine elektronische Registrierkasse einsetzen muss. Hier kann nun der Selbstständige frei entscheiden, ob er nun eine elektronische Registrierkasse unter Berücksichtigung der vorgenannten Anforderung im Rahmen seines Geschäftsbetriebes einsetzt oder lieber weiterhin Kassenberichte (z. B. im Rahmen einer offenen Kasse) führt, aus denen die Bareinnahmen und - ausgaben hervorgehen.

Setzt der Selbstständige jedoch ein elektronisches System zum Zwecke der Kassenführung ein, so müssen aktuelle und zukünftige Anforderungen der GoBD bzw. dem geplanten Kassengesetz Rechnung getragen werden. Ansonsten drohen bei Nichteinhaltung diverse finanzielle Sanktionen, welche überflüssig und teuer sind.

Wie bereits erwähnt, besteht die Möglichkeit bei Vorliegen diverser Zweifel an der Ordnungsmäßigkeit der Kasse von einer Kassen-Nachschau auf eine Außenprüfung überzugehen.

Deshalb:

Bitte fragen Sie in Ihrem konkreten Fall Ihren steuerlichen Berater! Die Inhalte dieser Lektüre dienen nicht als Ersatz einer Steuerberatung. 